\title{
THE IMMATURE STAGES OF Phoracantha recurva Newman, 1842 AND Phoracantha semipunctata Fabricius, 1775 (COLEOPTERA, CERAMBYCIDAE) AND A KEY TO LARVAE OF THESE SPECIES
}

\author{
MORELLI, E., ${ }^{1}$ BIANCHI, M. ${ }^{2}$ and SANCHEZ, A. ${ }^{2}$ \\ ${ }^{1}$ Sección Entomología, Facultad de Ciencias, Iguá, 4225, Montevideo, 11400, Uruguay \\ ${ }^{2}$ Protección Forestal, Facultad de Agronomía, Avda. Garzón, 780, Montevideo, 11900, Uruguay \\ Correspondence to: Enrique Morelli, Sección Entomología, Facultad de Ciencias, Iguá, 4225, Montevideo, 11400, \\ Uruguay, e-mail: emorelli@fcien.edu.uy \\ Received July 23, 2001 - Accepted February 5, 2002 - Distributed November 30, 2002
}

(With 34 figures)

\begin{abstract}
The description of the last instar larva and pupa of Phoracantha recurva Newman, 1842 and the redescription of the immature stages of Phoracantha semipunctata Fabricius, 1775 showing new characters of possible diagnostic value are presented in this work. A key of identification of both species based on these characters is also given.
\end{abstract}

Key words: Coleoptera, Cerambycidae, Phoracantha, immature stages.

\section{RESUMO}

Estágios imaturos de Phoracantha recurva Newman, 1842 e Phoracantha semipunctata Fabricius, 1775 (Coleoptera, Cerambycidae) e uma chave para larvas dessas espécies

O presente trabalho se refere à descrição do último ínstar larval e da pupa do Phoracantha recurva Newman, 1842, e à redescrição dos ínstares imaturos do Phoracantha semipunctata Fabricius, 1775, com base em novos caracteres morfológicos úteis para identificação das espécies. Além de apresentar uma chave para a identificação de larvas dessas espécies.

Palavras-chave: Coleoptera, Cerambycidae, Phoracantha, ínstares imaturos.

\section{INTRODUCTION}

In Uruguay many species of cerambycids are found attacking species of the Eucalyptus genus. Since identification of their immature stages is very difficult, descriptions and keys necessary to recognize them. During the last ten years, species of the Eucalyptus genus have been widely planted for industrial purposes in Uruguay. As a consequence, some accidently introduced insect pests like Phoracantha recurva Newman and Phoracantha semipunctata (Fabricius) could cause serious economic damage in the near future.

$P$. semipunctata was detected in 1932 and P. recurva was found in 1998 . Both species are widely distributed in the country. $P$. recurva adult size is $19 \pm 2 \mathrm{~mm}$. Antennae are about 1.5 to 2 larger than the body in males and slightly larger than the body in females. The elytra are yellowish brown, with a narrow incomplete zig-zag band before the middle, in most cases reduced to a small spot on each elytra, and in the apex there is a yellowish spot. The antennae have a spine curved outward on the third segment. $P$. semipunctata adult size is $22 \pm$ $3 \mathrm{~mm}$. Antennae are about 1.5 to 2 larger than the body in males and slightly larger than the body in females. The elytra are dark reddish brown or blackish brown with a narrow zig-zag yellowish band in the middle in the apex there is a yellowish spot (Wang, 1995). 
These species attack newly Felled timber or stressed Eucalyptus trees, usually killing their host. Larvae bore through the bark galleries along the cambium and floem. The mature larvae bore through the sapwood and then hardwood for pupation.

Duffy (1957, 1960, 1963) described the immature stages of $P$. semipunctata and presented a key to the neotropical species of the Cerambicinae, in which P. semipunctata was included. Duffy (1963) mentioned that mature larvae of both species are similar and that $P$. recurva mature larva may only be distinguished from $P$. semipunctata by the broadly oval or subcircular ocellar lens and the strongly sinuate front margin of the hypostoma.

This paper describes the last instar larva and the pupa of $P$. recurva and $P$. semipunctata based on new taxonomic characters which could be used for diagnosing both species. It also provides and a key to mature larvae of these longicorn beetles.

\section{MATERIAL AND METHODS}

$P$. recurva and $P$. semipunctata beetles were reared in the laboratory on one of their natural hosts (Eucalyptus globulus ssp. globulus logs). Neonate larvae were manually transferred to logs which were kept in a controlled environment chamber $\left(25 \pm 2^{\circ} \mathrm{C}\right.$ and photoperiod 12:12 h L:D). Mature larvae and pupae were removed from these logs in order to describe them. Larva head and pronotum of the pupa were examined with a Scanning Electron Microscope (SEM) Jeol-JEM- 1010. The larval and pupal characters were based on Duffy $(1957,1960,1963)$, Costa et al. (1988), and Stehr (1991).

\section{RESULTS}

\section{Phoracantha recurva Newman}

Description of the last instar larva (Figs. 1-14) Mature larva (Fig. 1). Total length: $26 \pm 5 \mathrm{~mm}$ $(n=50)$. Form robust and rather strongly depressed. Cuticle milky white with yellowish - brown setose area, chaetotaxy generally yellowish brown. Head (Figs. 4-5): maximum width of the head capsule $5 \pm 0.4 \mathrm{~mm}(\mathrm{n}=50)$, very retracted into prothorax. Median suture absent; and frontal suture indistinct. Temples without the broad ferruginous cuneiform band. Frontal clipeal suture well - defined with sinuous borders. Ocelli under the antennae. Quadrangular labrum (Fig. 6) with rounded external margin narrower towards the tormae. Numerous long setae in the external margin. Lateral scattered setae. Glabrous central area, framed by short scattered setae. Epipharynx (Fig. 7) with setose area entirely within the external margin. Short antennae (Fig. 8), 3-segmented, the first elongate with two external setae; the second segment with one internal seta; and the last one very small with long apical setae. Supraocelar area with 5 fine setae in a well-defined region (Fig. 31). Mouthpieces (Figs. 9-11) retracted. Symmetrical mandibles, strongly sclerotized with a broad base, mola absent. Maxilla (Fig. 12). Mala with triangular slightly rounded apex and elongated upper margin setae. Maxillary palp 3-segmented with a crown of medium setae located at the intersegmental region between the first and second segment. Cardo subtriangular and short; stipe with medium external setae. Labium (Fig. 13) globular, setose, subquadrangular submentum with two short central setae. Labial palps 2-segmented with a crown of medium setae located at the intersegmental region. Prothorax (Figs. 2-3) larger than the other thoracical segments. Pronotum with two broad setose areas at the lateral margin which extends towards the anterior region. Elliptic and median mesothoracic spiracles. Very short legs with indistinct segments. Abdomen with 10 distinct segments, one pair of annular spiracles on the I-VII segments. Abdominal tergite X (Fig. 14) with less abundant chaetotaxy and a pair of long setae at the edge of each median lobe. Anal opening Y-shaped between the three median lobes; setose area with long setae inserted between less numerous medium setae.

\section{Description of the pupa (Figs. 15-16)}

Total length $23 \pm 2 \mathrm{~mm}$, maximum width of pronotum $6.5 \mathrm{~mm}$. Exarate, milky white and glabrous. Head in dorsal view with vertex slightly visible. Antennae with spine curved outward on 3segment and hidden behind pro-and mesothoracic podotecas. Pronotum quadrangular, rounded upper border, anterior and lateral longitudinal fine striation and with a pair of short tubercles at the lateral margin (Fig. 33). Few spines with long setae at their base, scattered on the whole surface. Distal tubercles on the pterotecas. Mesothoracic podotecas protected behind the pterotecas. Abdomen elongated becoming narrower towards the last segments; dorsa of segments 1, 2, 3, and 4 with 3 irregular rows of small spiniform setae leaving a glabrous central region; dorsa of segments $5,6,7$, and 8 with a single row on each side. Spiracles visible from 1 to 6 segments. 

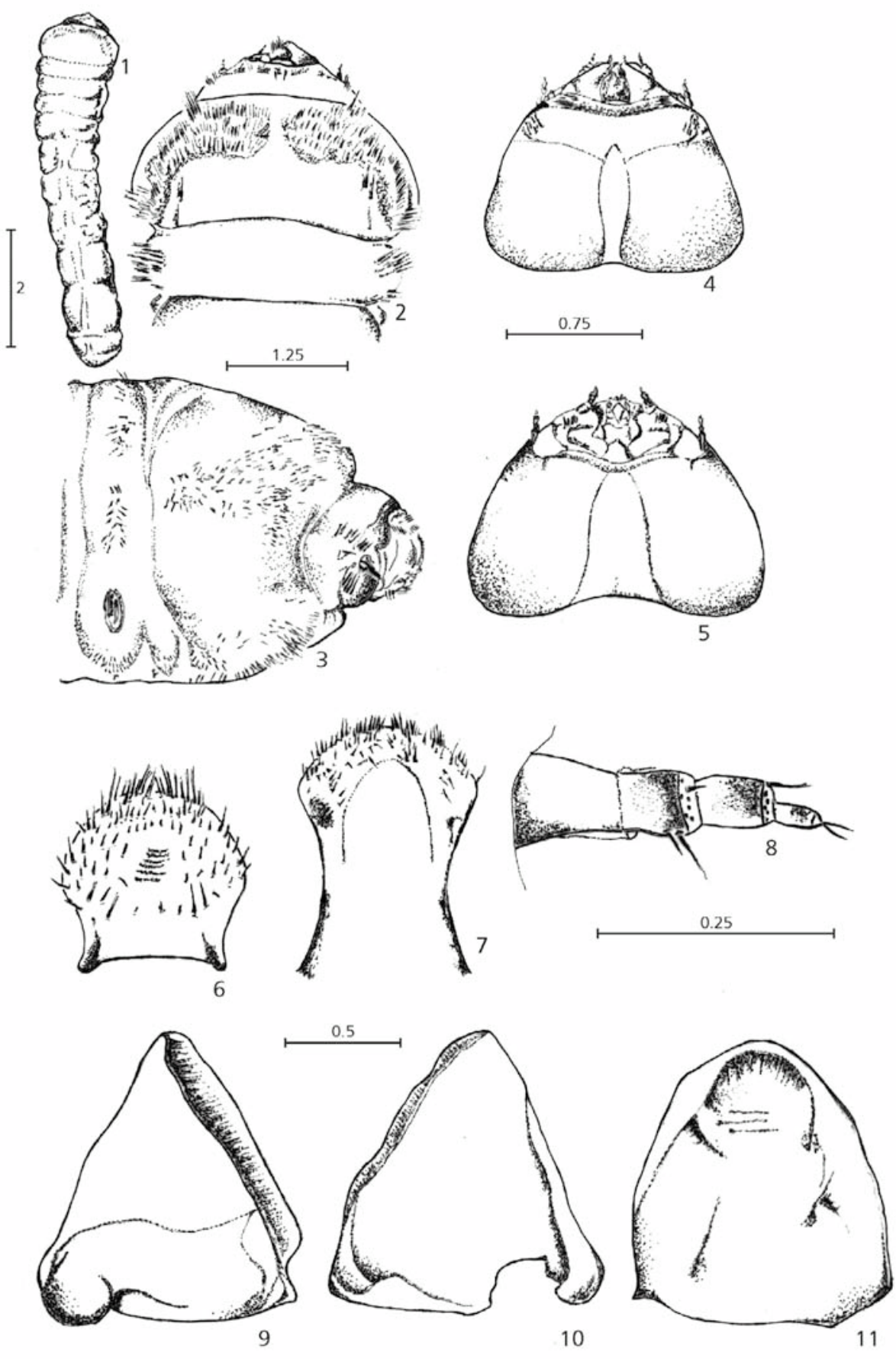

Figs. 1-14 - Phoracantha recurva. 1 - larva, dorsal view; 2 - head, $1^{\text {st }}$ and $2^{\text {nd }}$ thoracic segment, dorsal view; 3 - head, $1^{\text {st }}$ and $2^{\text {nd }}$ thoracic segment, lateral view; 4 - head, dorsal view; 5 - head, ventral view; 6 - labrum; 7 - epipharynx; 8 antenna; 9 - right mandible, ventral view; 10 - right mandible, dorsal view; 11 - right mandible, inner surface. Scale line in $\mathrm{mm}$. 

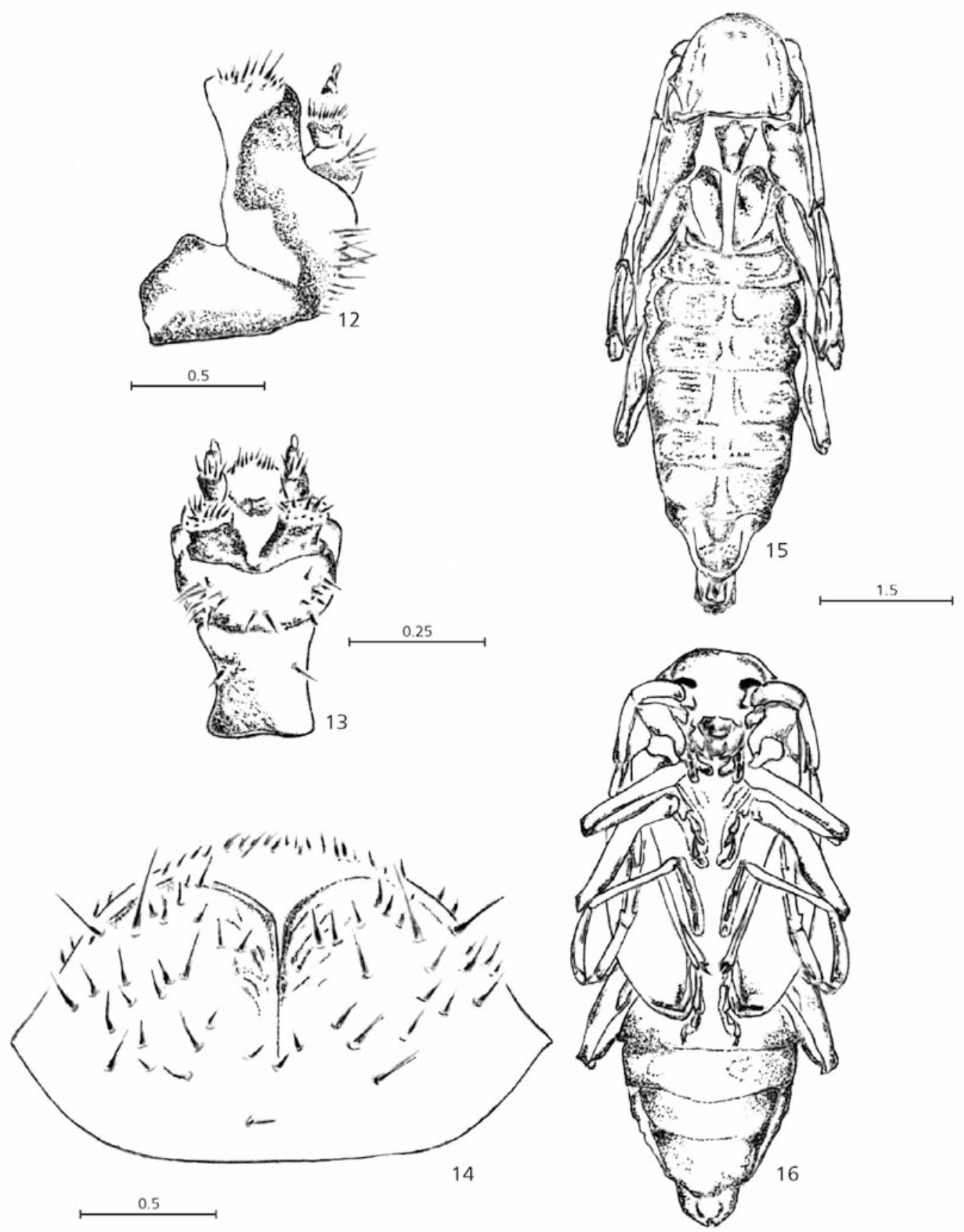

Figs. 12-16 - Phoracantha recurva. 12 - left maxilla, ventral view; 13 - labium; 14 - X-segment, ventral view; 15 - pupa, dorsal view; 16 - pupa, ventral view. Scale line in $\mathrm{mm}$. 


\section{Phoracantha semipunctata Fabricius}

Description of the last instar larva (Figs. 17-28)

Mature larva. Total length $26 \pm 4 \mathrm{~mm}(\mathrm{n}=60)$, maximum width of head capsule $5 \pm 0.3 \mathrm{~mm}(\mathrm{n}=60)$.

Form robust and rather strongly depressed. Cuticle milky white with setose pale brown area on the upper and lateral border of the prothorax, chaetotoaxy generally pale brown. Head (Figs. 1920) prognatous, very retracted into prothorax. Epicranial suture visible. Labrum (Fig. 21) subquadrangular with external margin slightly rounded; less contricted towards tormae region than is the case with $P$. recurva. External and lateral chaetotaxy with fine long setae; central region with a pair of long setae and an area of micro-sensilla near the base.

Epipharynx (Fig. 22) with very long setae covering all the anterior and upper-lateral margin. Two setose areas on the anterior border framing a glabrous central area. Antennae (Fig. 24) 3segmented, the first segment longer than the others with two external and subequal setae; the second with a pair of dorsal setae on the distal margin; and the last segment finer than the others, elongated with a crown of apical and short setae with long setae intercalated. Distinct ocelli located at the antenna base and an inner seta near the ocellus. Temple with a pigmented cuneiform area behind the antennae. Supraocelar setose area with 7 setae distributed in a row towards the pronotum (Fig. 32). Mouthpieces (Figs. 25-27) retracted, very sclerotized symmetrical mandibles with broad base. Molar region absent and scissorial region cuneiform. Inner surface of the mandibles concave. Maxilla (Fig. 23) with functional galea and lacineae. External border with a row of very long setae. External region of the stipe setose. Maxillary palp with 3 articles. Very long setae between the first and second segment. Labium (Fig. 23) with prementum and mentum globosus with long and fine pubescence. Labial palpi with two articles and very pubescent intersegmental region. Subquadrangular prothorax (Figs. 17-18) larger than meso-and metothorax; rounded lateral margins. Anterior and lateral margin with setose area more dense at the external margin, brown pale chaetotaxy. Abdomen with 10 segments. The last segment (Fig. 28) with rounded distal margin, its surface covered with scattered fine setae and a long central seta distinguishable on each anal lobe.

\section{Description of the pupa (Figs. 29-30)}

Total length $24 \pm 2 \mathrm{~mm}$, maximum width of pronotum $7.0 \mathrm{~mm}$. Adectic and exarate, milky white and cuticle glabrous. Vertex hardly visible dorsally. Subquadrangular pronotum with upper margin rounded. Lateral borders with a medium conic lateral tubercle located at each side. Pronotum surface with central fine striation, spines with long fine setae at their base distributed in groups in the center and upper and lateral margins (Fig. 34). Pterotecas with distal tubercles. Abdomen elongate, becoming narrower to wards the distal segments. Dorsal segments 1, 2, and 3 with 3 irregular rows of small spiniform setae leaving a glabrous central region. Dorsal segments 4 and 5 with a pair of irregular rows and segments 6,7 , and 8 with a single row on each side. Spiracles visible from segments 1 to 6 .

\section{Key to larvae of the species of Phoracantha in Uruguay}

Temples with broad ferruginous cuneiform band behind the antennae bases. Supraocelar area with 7 setae, three of them aligned towards the pronotum. Abdominal tergite $\mathrm{X}$ with uniform setose area and distinctly central setae at each median lobe $P$. semipunctata. Temples without the broad ferruginous cuneiform band. Supraocelar area with 5 fine setae in a well-defined region. Abdominal tergite $\mathrm{X}$ with less abundant chaetotaxy and a pair of long setae on the border of each median lobe $P$. recurva.

\section{DISCUSSION}

$P$. recurva and $P$. semipunctata are present in Uruguay. The identification of larvae of both species is difficult. The characters used in this work were the presence or absence of the ferruginous band of the temples, and the chaetotaxy of the supraocellar region and the X abdominal tergite. Duffy (1957, 1960, 1963) characterized $P$. semipunctata larvae by the spiracule shape, temples, and ampule texture. As described in this paper, chaetotaxy present at both sites of the head and on the last abdominal segment of $P$. recurva and $P$. semipunctata would be an important character to consider in addition to those given by Duffy $(1957,1960,1963)$. Pupae of these Phoracantha species can be distinguished by the presence of a spine curved outward on the 3-segment of the antennae in P. recurva and by the chaetotaxy of the more conspicuous pronotum in P. semipunctata. 

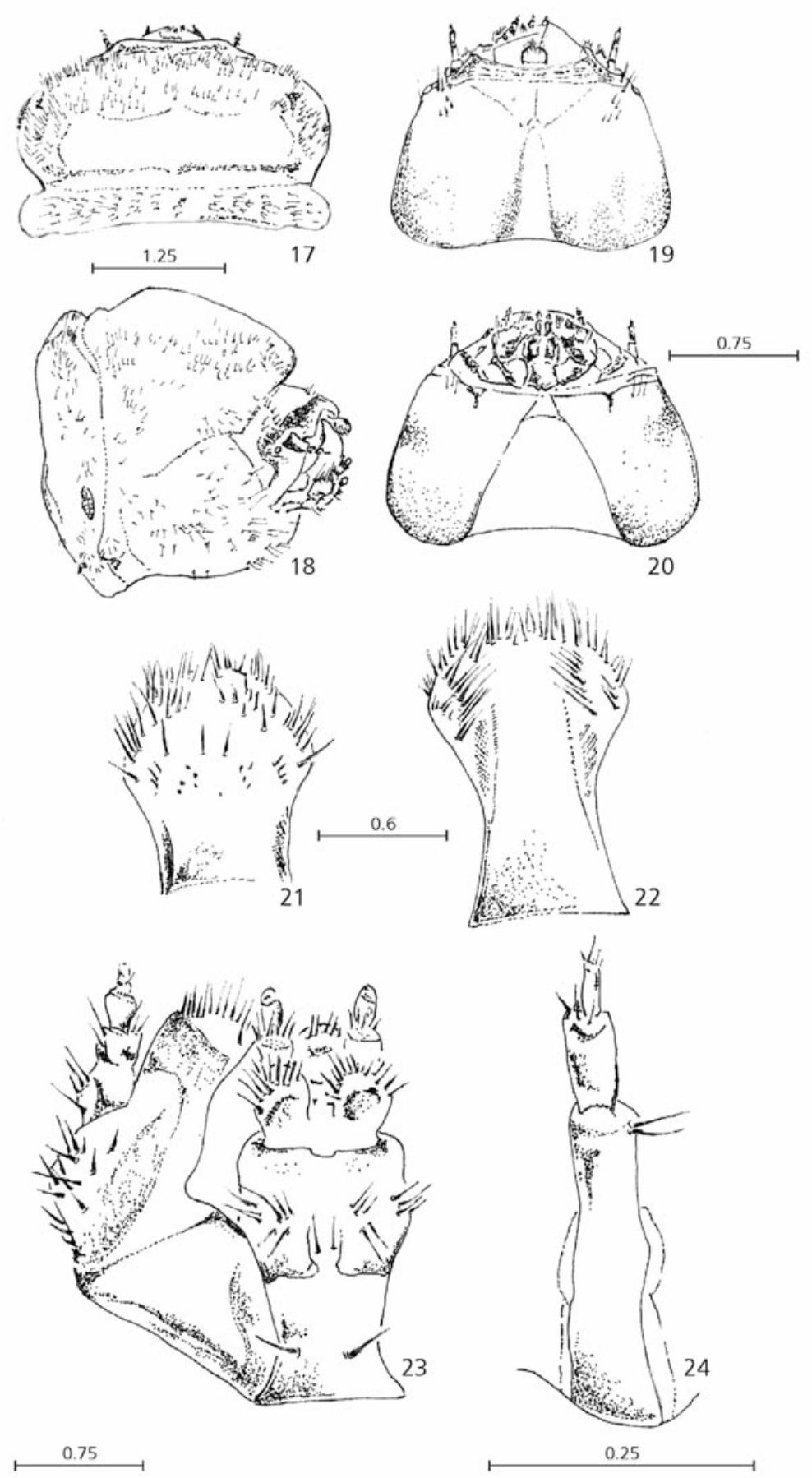

0.75

Figs. 17-24 - Phoracantha semipunctata. 17 - head, $1^{\text {st }}$ and $2^{\text {nd }}$ thoracic segment, dorsal view; $18-$ head, $1^{\text {st }}$ and $2^{\text {nd }}$ thoracic segment, lateral view; 19 - head, dorsal view; 20 - head, ventral view; 21 - labrum; 22 - epipharynx; 23 - labium and maxilla, ventral view; 24 - antenna. Scale line in $\mathrm{mm}$. 

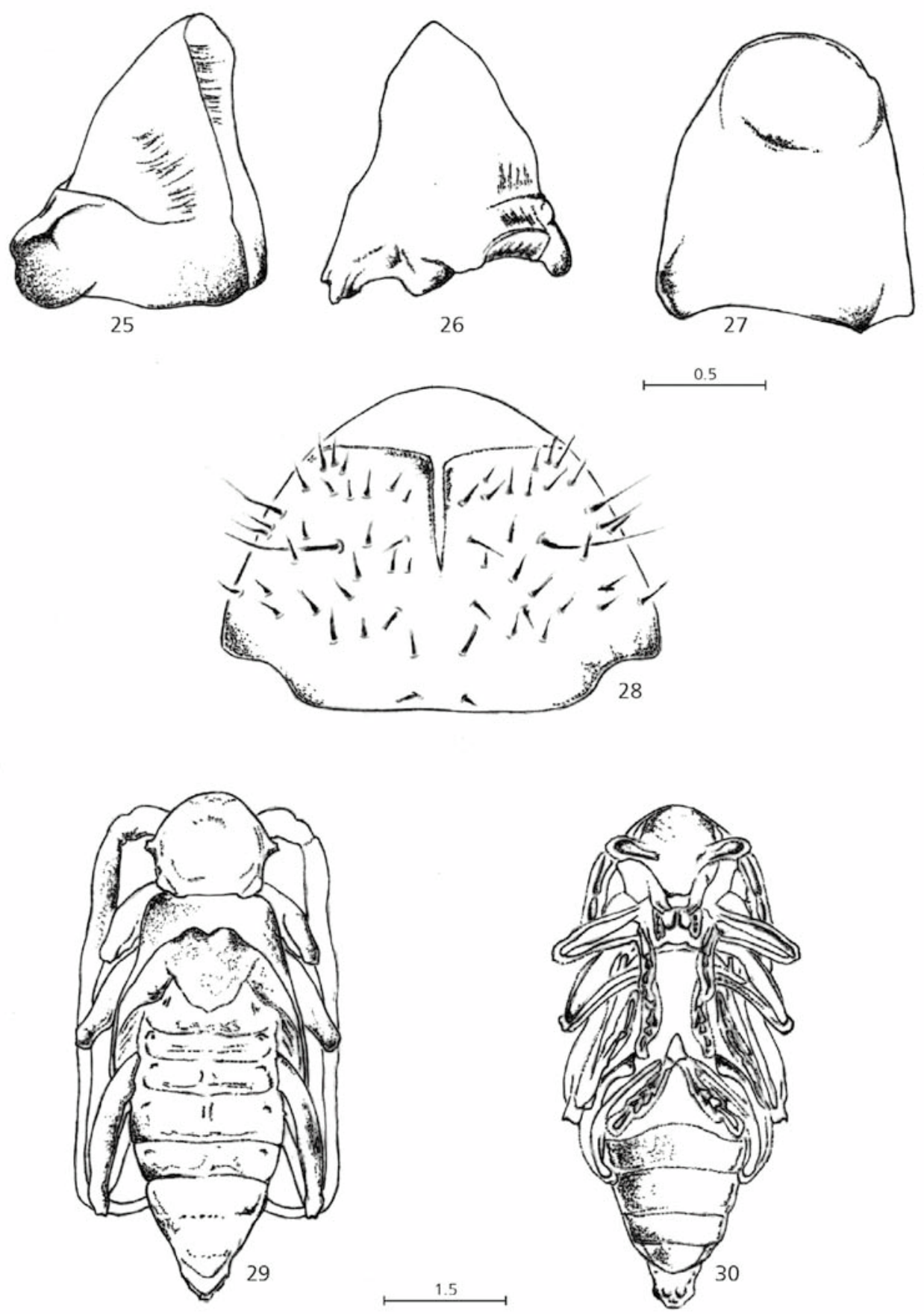

Figs. 25-30 - Phoracantha semipunctata. 25 - right mandible, ventral view; 26 - right mandible, dorsal view; 27 - right mandible, inner surface; 28 - X-segment, ventral view; 29 - pupa, dorsal view; 30 - pupa, ventral view. Scale line in $\mathrm{mm}$. 

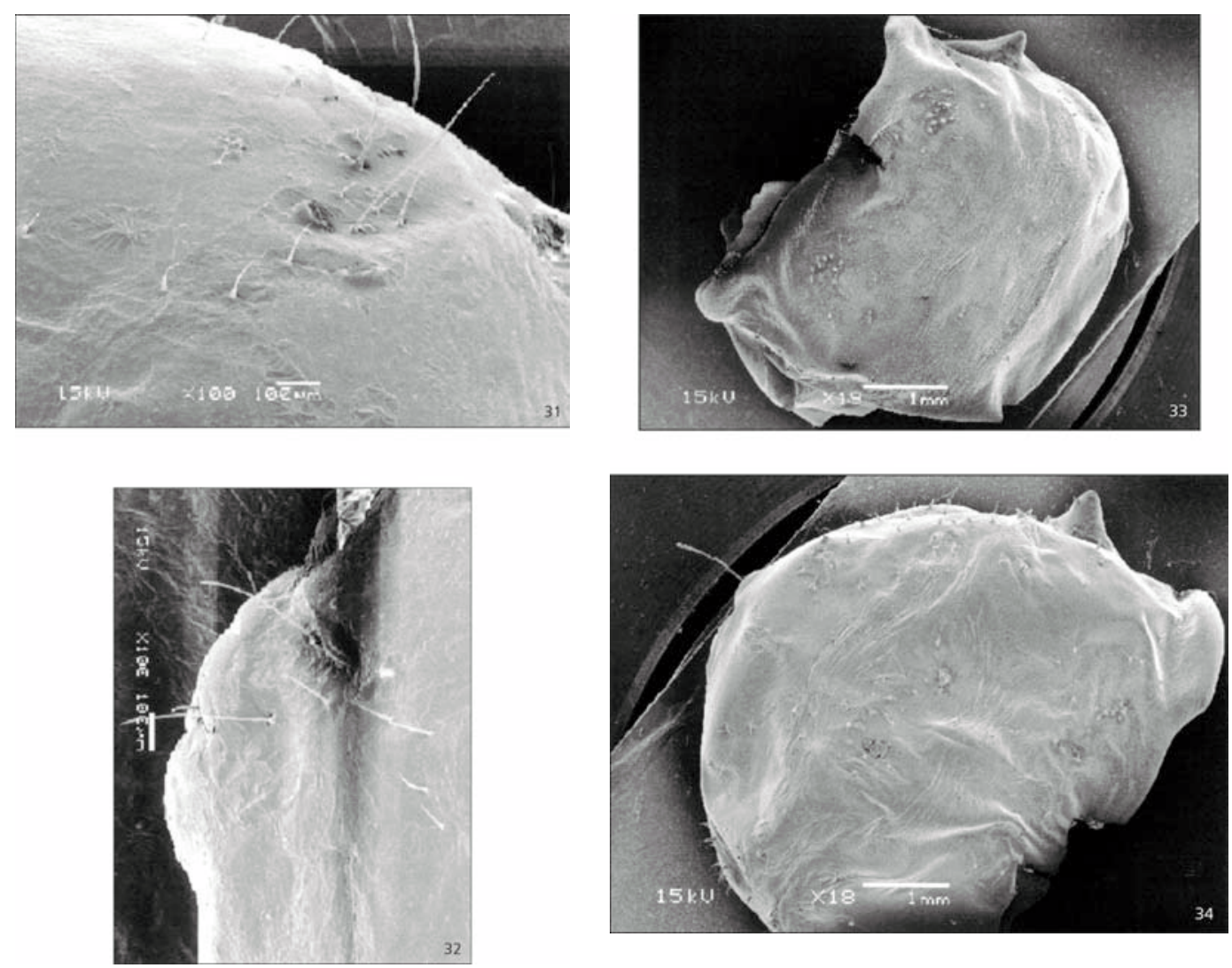

Figs 31-34 - 31 - Phoracantha recurva, detail of the supraocelar area; 32 - Phoracantha semipunctata detail of the supraocelar area; 33 - Phoracantha recurva, pronotum of the pupa, dorsal view; 34 - Phoracantha semipunctata, pronotum of the pupa, dorsal view.

Acknowledgments - We want to thank Dr. M. Monné for encouraging us to develop this research.

\section{REFERENCES}

COSTA, C., VANIN, S. A. \& CASARI-CHEN, S. A., 1988, Larvas de Coleoptera do Brasil. Museu de Zoologia, Universidade de São Paulo, FAPESP, 282p., 165 PL.

DUFFY, E., 1957, A monograph of the immature stages of African timber beetles (Cerambycidae). British Museum, London, pp. 38-41; 113-117.

DUFFY, E., 1960, A monograph of the immature stages of neotropical timber beetles (Cerambycidae). British Museum, London, 327p., XIII.
DUFFY, E., 1963, A monograph of the immature stages of Australasian timber beetles (Cerambycidae). British Museum, London, pp. 68-74.

STEHR, F. W., 1991, Immature insects. F. W. Stehr, Kendall/ Hunt Publishing Company USA, v. 2, 975p.

WANG, Q., 1995, A taxonomic revision of the Australian Genus Phoracantha Newman (Coleoptera: Cerambycidae). Invertebr. Taxon., 9: 865-958. 